\title{
Political Polarization During 2017-2021
}

\author{
Akshay Padala ${ }^{1}$ and Lee Conrad ${ }^{\#}$ \\ ${ }^{1}$ Little Central High School, Little Rock, AR, USA \\ "Advisor
}

\section{$\underline{\text { ABSTRACT }}$}

During the Trump era there was a significant rise of hate crimes, racial bullying, and violence against the LGBTQ+ community which can be explained by political polarization. Both major political parties were pushed to the far ends of the spectrum to counteract the influence of the other side. We tested how this polarization occurs at the level of individual political issues, and study the political factors under Trump that contributed to it. We used a survey research method to collect data on peoples' beliefs over 5 different contentious political topics (abortion, climate change, gun control, healthcare, and immigration). This data was compared to data from studies performed in 2016 (pre-Trump). To ensure standardization of the data, our survey used the same questions as the previous surveys. Along with the questions gauging opinion, we also included an individual question per issue that gauged how the participant formed that opinion. Compared to 2016 there was a shift towards more government involvement and regulation in the areas of healthcare and gun control, respectively. There was a shift towards environmental protection, and less stringent immigration standards. More participants were in favor of abortion. Most participants said they formed ALL of their political opinions individually. However, social media and major news outlets had played a role in shaping opinions about abortion and environment, respectively. Compared to 2016 surveys there was a significant change in public opinion about various issues of contemporary importance, partly influenced by political polarization and by social media and news outlets.

\section{Introduction}

One of the biggest issues that we face within the United States is the issue of rising ethnic nationalism. This issue challenges the foundation of society and has exponentially increased the threat of violence. It is also much more pressing, however, due to the fact that people like Donald Trump have risen to power in American politics. Trump has used his platform to espouse anti-immigrant, sexist, and racist beliefs that have fueled a new wave of hate in the US. This rhetoric has played a role in the increase of racial violence in both hate crimes and racially motivated bullying (Nacos et. al 2020). The role that this rhetoric plays also occurs in more insidious ways, fueling discriminatory microaggressions within the everyday lives of minorities. Given the outrageous role the Trump Administration has played in shining the spotlight on a new wave of hatred in the US, it is important to recognize the incredibly important role that the rhetoric of politicians plays in shaping the political landscape of the nation.

Polarizing rhetoric often comes from identifying with a larger group of people. This tribe mentality fosters the creation of an in-group and an out-group. Those with negative conceptions of the out-group tend to be more willing to resort to violence against that group. One example of this is in the case of xenophobia. Due to the rising antiimmigrant sentiment that is spreading globally, politicians are using policy that is oriented towards stopping the flow of immigrants to garner votes. This rhetoric plays to the fears of the constituents and focuses on that very logic of group identification to spur fear of the out-group. Research has found that those who identify more with the socially constructed in-group are more likely to orient with xenophobic rhetoric and policies (Perez, 2015).

Given the relevance of this topic to the current political situation, the goal of this project is to analyze how Trumpian rhetoric and the political situation fostered by the Trump administration have changed the political opinions 
of Americans. It is important to analyze and collect this data in the context of Trump because he represents a more extreme case of the issue, where political rhetoric has led to an uptick in violence.

\section{Literature Review}

Literature review included extensive searches of the JSTOR, EBSCO, and Google Scholar. Key words used for the literature review included, political polarization, politics, policy, polarization, Trump, abortion, Affordable Care Act, gun rights, immigration, and global warming. Although political polarization has been discussed in the past (Poole et al., 2007), the search focused on trends from 2010 onwards. Poole had created a spatial map after analyzing all of the roll-call votes in the first 108 Congresses $(1789$ - 2004), and concluded that political polarization started with the demise of the three-party system in early 1980s and accelerated through 1987-2006 Congress. They contend that primaries and gerrymandering, institutional forces generally believed to cause polarization, were not factors in the modern trend of polarization, making political rhetoric an important factor. Literature review regarding political rhetoric is organized below into three perspective. The first factor is how politicians use different rhetorical strategies to affect public opinion, and how that plays a role in bringing constituents in line with their political views. The second factor is the shift towards opinion-based media that passes judgements about politics rather than presenting the information in a neutral manner, which has led to news outlets being branded as politically biased. The last factor is the role that presidential rhetoric can play. These factors take into account both the political situation and rhetoric of politicians to develop a nuanced understanding of the current political climate.

\section{Perspective 1 -- Politicians and Constituents}

The intended model to explain the relationship between politicians and their constituents mostly assumes that politicians always work to achieve the goals of their constituents. However, this view fails to take into account how politicians use rhetoric to bring their constituents in line with their beliefs. (Matsubayashi, 2013) discusses three ways that politicians alter the opinions of their constituents in their favor: targeted political proposals, rhetorical appeals, and appeals to an in-group, out-group mindset. In the context of this paper's research, the in-group, out-group mindset is most important. According to (Matsubayashi, 2013), the creation of an in-group and an out-group creates a situation where those within the in-group are more likely to identify with the corresponding ideals/policies regardless of whether or not they are informed on the issue. This leads to a dangerous form of politics where decision-making is based entirely off of a demagogy as opposed to personal research, which poses a threat to the democratic process, which demonstrates the shift towards a more polarizable kind of politics.

In the context of in-group creation in politics, it is important to understand their composition. (Montiel et. al,2016) presents data on how both ends of the political spectrum use different tools to foster the creation of the ingroup and out-group mentality. The study analyzed political debates over reproductive rights using a mixed-methods approach that focused primarily on text mining political speeches to link political ideology to broader themes. The results showed that conservative political rhetoric was almost always backed up by a religious appeal rooted in Christianity, and liberal political rhetoric was often backed up with appeals to rationality. Questions of gender equality, LGBTQ+ rights, etc. are often argued in the context of Christian ideals by conservative politicians. This is dangerous to democracy at two levels. First, it violates a core tenet of the first amendment that declares that church and state should be kept separate. Fusing the church with politics risks taking away religious freedoms for those who do not follow the "dominant" religion. Second, it allows policy positions to be regarded as moral truisms as opposed to actions with consequences, which kills political dialogue and keeps politicians in echo chambers (Montiel et al., 2016). It is important to analyze how certain types of rhetoric affects the American people, and how it can be broken down. 


\section{Perspective 2 -- Media and Public Opinion}

Due to the contentiousness of the political stances of the Trump administration, a hard line was drawn between the American left and right. One of the most prominent arenas for this split is through the news, where "biased liberal media" and the alleged censorship of conservative viewpoints has led to the rise of a new kind of media oriented towards supporting the political beliefs of one party. Examples include Fox News and political commentators like Ben Shapiro who primarily focus on spreading conservative viewpoints. This is indicative of a shift towards "high-conflict" reporting. High-conflict reporting is defined by Forgette et al. (2006) as reporting that is centered around generating controversy or attacking or defending a certain viewpoint, as opposed to simply presenting information. To test the effects of this kind of reporting, the researchers took poll data on the public opinion of CNN viewers after viewing CNN's crossfire of the State of the Union address. The crossfire focused on refuting claims made in the address from a partisan standpoint. The researchers found that for all individuals tested, they felt less confident in their politicians and institutions. While having the ability to question institutions is obviously essential, this erosion of trust in institutions can have negative effects: for example, a large portion of individuals refused to adhere to the government's mask mandate due to hearing anti-mask arguments from news outlets like Fox. Smith and Serles found that opinionbased shows are increasingly used by news channels as they are known to have greater influence on public opinion than news coverage (Smith et al. 2013). This shift towards partisan news unfortunately allows people to isolate themselves, creating virtual echo chambers which increases hostility and polarization towards those who do not share the same political beliefs.

\section{Perspective 3 -- Political Rhetoric and Hatred}

From its beginning in 2016, the Trump administration has been at the center of numerous debates regarding the marginalization of minorities. The travel ban, anti-immigrant preaching, the "build the wall rhetoric," and the repeal of rights to LGBTQ+ people all highlight the contentiousness of the Trump administration on their stances for the rights of minorities. According to Nacos, Shaprio, and Bloch-Elkon, (2020), there has been a steady uptick in violence towards minorities, due to the nature of what they term as "Trumpian Rhetoric" during 2017-2021. For these authors, Trumpian rhetoric is defined majorly by an in-group, out group mentality that plays into the already existing prejudices of a group of people through language that encourages fear of - or violence toward - those in the outgroup. This relationship between Trumpian rhetoric and attitudes towards minorities highlights the importance of understanding how political rhetoric polarizes public opinion.

In the context of xenophobia and anti-immigrant rhetoric, (Perez. 2015) discusses the effect of xenophobic rhetoric from politicians on minority communities. According to Perez, xenophobic rhetoric is any rhetoric that "raises the saliency of an ethnic identity while devaluing its worth." This can be likened to Trumpian rhetoric, which gave a new level of importance to the ethnic identities of Latinx people as the key issue of Trump's election, while also devaluing them as unworthy to be in the United States. Instead of focusing on the negative effects of xenophobia, Perez (2015) focuses on how xenophobia can polarize communities against immigrants. Using a survey of 1203 Latinx people, Perez (2015) found that those Latinx people with higher identification with their ethnic identity would be more likely to act against xenophobic rhetoric, to preserve the pride of the group. This research illustrates how polarization can have a positive effect by increasing one's pride within their own culture but also shows the degree to which xenophobic rhetoric has the potential to affect people in the opposite way.

Gap

Despite the extensiveness of the aforementioned research, there is still a gap in academia concerning specific research on how the political rhetoric affects public opinion on specific politically contentious issues. Matsubayashi and Montiel have a strong analysis on the relationship between politicians and their constituents but do not focus on President Trump. Forgette et al. do not focus on specific media outlets that were known to be supportive of and supported by him. Perez focuses on xenophobia broadly and conducted research after the Trump era, and Nacos et al. 
do not focus on specific policies nor do they compare with the pre Trump era. This focus on specific policies is important because those policies can be warped to be the most insidious yet potent manifestation of prejudice in the US by making Americans support policies that systemically disparage minority communities. This research attempts to fill this gap, using survey research to see how the Trump era changed the political opinions of Americans.

\section{Methods}

To evaluate the effect that Trump era rhetoric had on the political opinions of Americans, a survey was conducted on a set of geographically distributed people who are eligible to vote. The survey was created using Google Forms and was spread using a snowball distribution method through several social media platforms, including Instagram and Facebook, as well as through email. A survey was used for this study for three reasons. First, it adds the aspect of anonymity, which encourages those participating to be more open about their views without a fear of judgement which allows for the most accurate results. Second, it keeps the response choices concise making them easier to compare. Lastly, it is the most efficient method of data collection during the COVID pandemic, as it does not require participants to leave their personal spaces to complete the survey.

Given that we would have to compare this survey to pre-Trump data regarding political opinion, the survey results were compared with data on public opinion from 2016, in close proximity to, or before, when Trump was elected president. To standardize data across the studies, we used questions from several surveys that were administered in 2016. These past surveys were comprised of three surveys from the Gallup news organization, which covered immigration, climate change, and abortion, one survey from Health Affairs that covered differences in opinion regarding healthcare, and one survey from the PEW research center that covered political opinion about gun control.

The survey was created surrounding the five aforementioned political issues. These five issues were chosen based on previous academic papers. In the context of rising immigration, rising xenophobic rhetoric in the mid 2010's was causing an increase in violence against Latinx communities, making it a cogent topic of political debate (Perez 2015). This is further magnified by the xenophobic rhetoric of the Trump campaign (Nacos et. al 2020). Climate change and gun control were also used as political debates for this survey because they have shown a unique ability to be divisive as compared to other issues, which makes it central to understanding how the Trump era polarized political opinion (Matsubayashi 2013). Abortion meets the bar for contentiousness because of its ability to draw in multiple perspectives that are backed up by different ideals, i.e. Religion, social justice, and science (Montiel et al, 2016). Lastly, healthcare was used as a category both because of Trump's campaign promises regarding the Affordable Care Act (ACA) and the ability for healthcare to be an especially divisive political issue (Montiel et al, 2016).

For the survey questions, they were personalized to the specifics of each section, as it would be reductive to approach different political debates in the same way. For each section, the number of questions varied from 3-7. Among all the sections, there was a question that asked what media the surveyee was exposed to that shaped their opinions on that issue. This allowed us to include the second level analysis that tried to understand the main causes behind the shifts in political opinion. The section labeled abortion only had one specific question that asked the surveyee to share whether they feel abortion should be legal, illegal, or legal under some circumstances. The section labeled healthcare had two specific questions: one that asked what the surveyee's opinion was on the ACA, and one that asked what role the government should play in healthcare. The second question was included for this section because the question of state control of the free market was an important political one that needed to be examined for opinion shifts. For the gun control section, the survey asked a litany of questions that gauged the opinions on background checks and restrictions on firearms. The section on immigration asked a singular question about the current levels of immigration. Lastly, the section on climate change asked whether the economy or the environment should be preferred and whether or not the surveyee felt as though current climate discourse was exaggerated.

Once the data was collected, the results were compared to the aforementioned surveys to see if there were significant differences between the proportions of respondents in the surveys. Given the differences in the sample 
sizes of the surveys, multiple two-sample $\mathrm{Z}$ tests were used to compare each response for a given variable. All responses were converted to proportion of the individual sample size. For each analysis, the proportions and sample size were entered. A conservative estimate of the p-value was generated using a two-sided analysis and an alpha=0.05.

\section{Results}

A total of 141 responses were received. All respondents were over the age of 18 years. 59.6\% of the respondents were female (chart 1). The majority of the sample identified themselves as Asian (58.1\%), followed by Caucasian (29.1\%), African American (8.5\%), and Latinx (3.5\%). Nearly three-quarters of the respondents consumed mainstream news (74.5\%). Among the mainstream news consumers, CNN was consumed by most $(35.5 \%)$ followed by ABC and MSNBC (6.5\% each), CBS (5.7\%), NPR and Fox News (5\% each). Over a quarter of the respondents did not consume mainstream news (25.5\%). These respondents received most of their political information from social media (52.7\%) and political commentaries (15.4\%). Very few of the non-consumers of mainstream news received political information directly from the politicians $(2.2 \%)$ whereas $29.7 \%$ used other sources for which details are not available. Regarding exposure to Trump's words, only $27.7 \%$ received information from Twitter and speeches whereas $72.3 \%$ relied on secondary sources such as social media and news. The majority of the respondents felt that the media that they consumed mainly portrayed Trump in a negative light $(85.1 \%)$.

There was a significant shift in public opinion regarding most questions in the survey compared with the surveys from 2016. Regarding the attitude towards abortion, significantly higher proportion of respondents in this survey felt that abortion should be legal under all circumstances compared to the 2016 survey (42.6\% (post) vs. 29\% (pre), Z -3.14, $\mathrm{p}=0.0016$ )(Fig. 1). Similarly, significantly fewer respondents in this survey indicated that abortion should be illegal compared to the 2016 survey ( $5 \%$ vs. 19\%, Z 4.01, p = 0.00001). However, there was not a statistically significant change in the proportion of respondents that felt that abortion should be legal under some circumstances $(52.5 \%$ vs. $50 \%, \mathrm{Z}-0.62, \mathrm{p}=0.528) .89 .4 \%$ of participants reported that they developed their views regarding abortion on their own, $7.1 \%$ reported that it was formed from social media, $2.8 \%$ said it was formed from political commentators, and $0.7 \%$ said it was formed from news outlets (Fig. 7).

Significant shifts were also seen in the context of healthcare. A much larger portion of participants felt as though they were favorable to the ACA $(85.1 \%$ vs. $40 \%, \mathrm{Z}-9.43, \mathrm{p}=0.00001)$ (Fig. 2). There was a significant shift towards the belief that the government should play a major role in healthcare $(73 \% \mathrm{vs} .58 \%, \mathrm{z}-3.2298, \mathrm{p}=.00124)$. There was not a statistically significant change in the amount of people that believed that the government should play a minor role in politics $(24.1 \%$ vs. $22 \%, \mathrm{Z}-0.5, \mathrm{P}=0.617)$. Lastly, there was a significant shift away from the belief that the government should play no role in politics $(2.8 \%$ vs. $18 \%, \mathrm{Z} 4.44, \mathrm{p}=0.00001) .68 .8 \%$ of participants said they formed their views on healthcare on their own, $14.2 \%$ said it was formed from news outlets, 5.7\% said it was formed from political commentators, $9.2 \%$ said it was formed from social media, and $2.1 \%$ said it was directly from a politician.

On the question of gun control, the shift indicated a clear trend. First, the participants of this survey demonstrated that there was a significant shift towards the belief that there should be background checks for gun sales (95.7\% vs. 81\%, Z -4.52, p=0.00001) (Fig. 3). A significant number of participants also shifted towards the idea that people on no-fly lists should not be allowed to purchase firearms (94.3\% vs. 71\%, Z -4.52, p=.00001). More participants agreed with the idea that there should be a ban on high capacity ammunition clips, as well as a ban on assault style weapons $(89.4 \%$ vs. 50\%, Z -8.39, p=0.00001) and (85.8\% vs. $52 \%, \mathrm{Z}-7.26$, p=0.00001) respectively (Fig. 4). Lastly, many agreed with the proposition that a federal database should be created to track all gun sales $(90.8 \%$ vs. $60 \%, \mathrm{Z}-6.9, \mathrm{P}=.00001)$. All of these results indicate that the participants had shifted towards regulation. $74.5 \%$ of participants said they formed their views regarding gun regulation on their own, $9.9 \%$ said it was formed from social media, $2.8 \%$ said it was formed from political commentators, and $12.8 \%$ said it was formed from news outlets. 
On the question of immigration, all opinions regarding levels of immigration experienced significant shifts over the Trump era. There was a significant increase in the proportion of people who believed that immigration should be kept at its current level (52.5\% vs. 38\%, Z-3.19, p=0.001) (Fig. 5). There was also an increase in the proportion of people who believed that immigration should be increased from its current level (31.9\% vs. 21\%, Z -2.72, $\mathrm{P}=0.0065)$. Lastly, there was a decrease in the proportion of people who believed that immigration should be decreased from its current level $(15.6 \%$ vs. $38 \%, \mathrm{Z} 4.9$, p=0.0001). $73 \%$ of the participants said that their views on immigration were formed on their own, $7.8 \%$ said it was formed from social media, $4.3 \%$ said it was formed from political commentators, $14.2 \%$ said it was formed from news outlets, and $0.7 \%$ said it was formed directly from the words of a politician.

Lastly, on the topic of climate change, there was a significant shift towards prioritizing the environment at the expense of the economy $(84.4 \%$ vs. $56 \%, Z-6.05, p=0.00001)$ (Fig. 6). There was a significant shift away from the idea that the seriousness of climate change is exaggerated $(14.9 \%$ vs. $34 \%, \mathrm{Z} 4.35, \mathrm{p}=0.00001)$. There was a significant shift towards the idea that the seriousness of global warming is correct in the status quo $(37.6 \%$ vs. $25 \%$, $\mathrm{Z}$-3.04, $\mathrm{p}=0.00236)$. Lastly, there was not a significant change in the proportion of people who believed that the seriousness of climate change was underestimated $(47.5 \%$ vs. $40 \%, \mathrm{Z}-1.7, \mathrm{p}=0.089) .57 .4 \%$ of the participants said that their views regarding climate change were formed on their own, $14.9 \%$ said those views were formed from social media, 2.8\% said it was formed from political commentators, $24.1 \%$ said it was formed from new outlets, and $0.7 \%$ said it was formed directly from the words of a politician.

\section{Fig 1: Attitude Towards abortion}

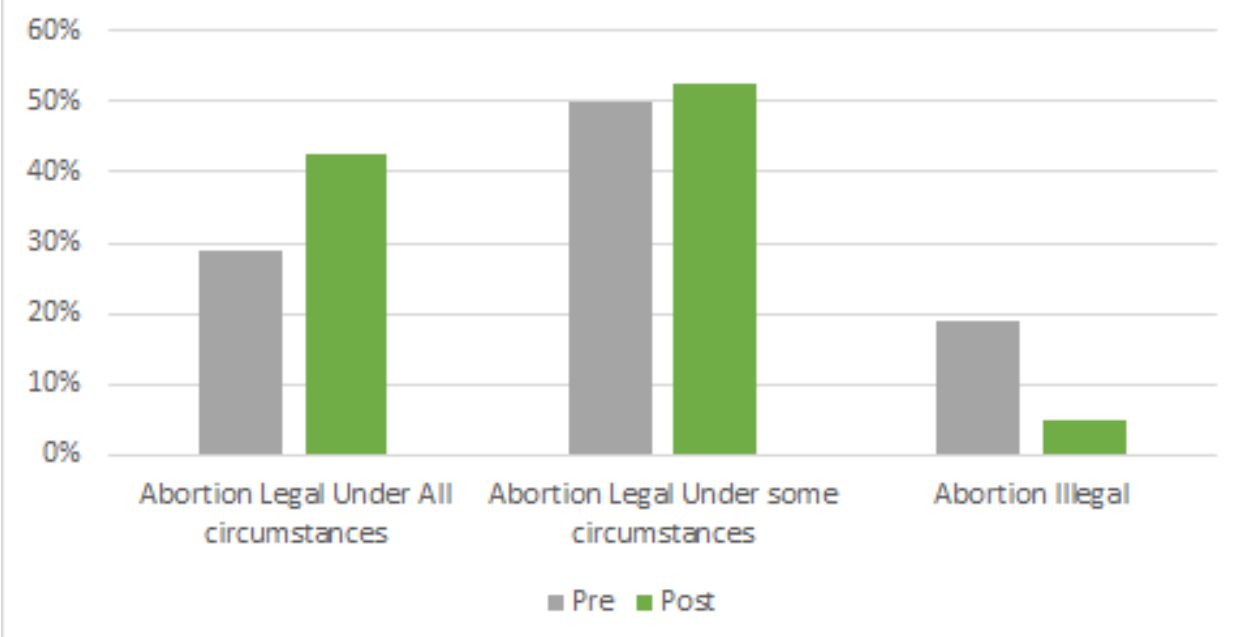

Figure 1: Attitude towards Abortion 


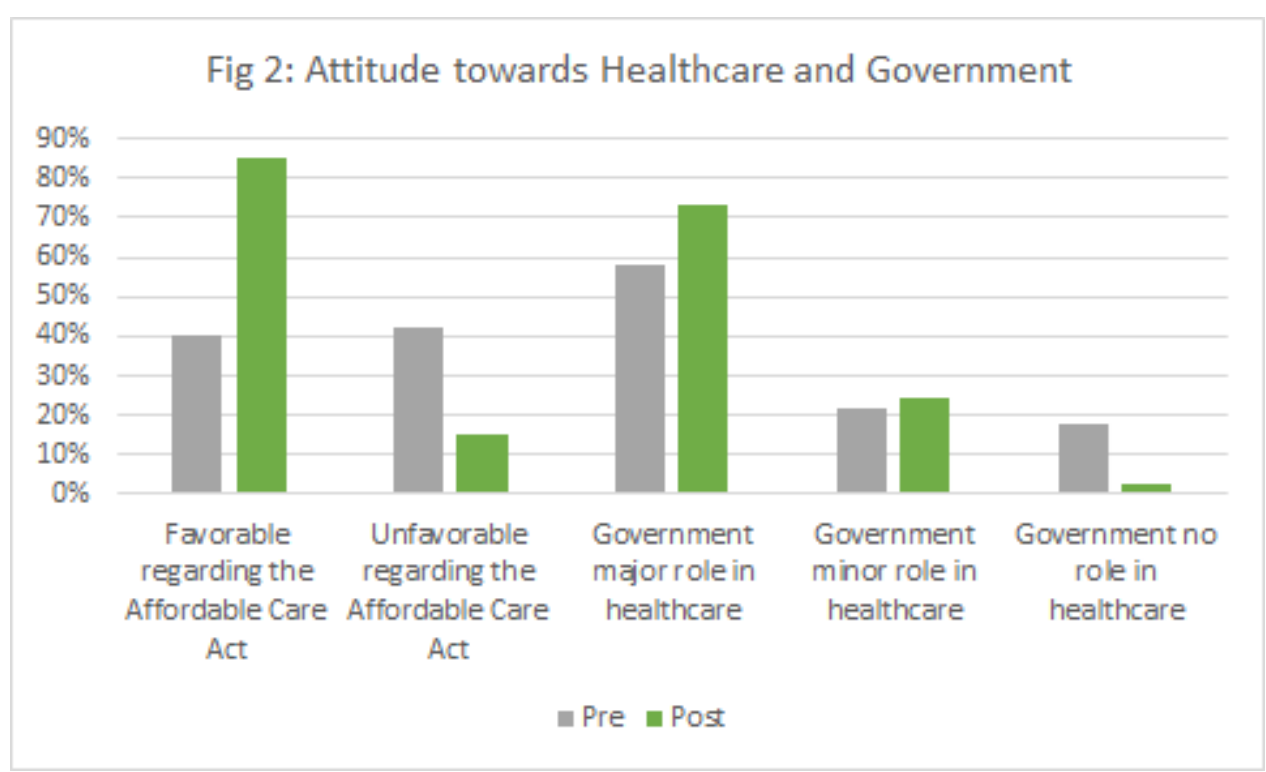

Figure 2: Attitude towards Healthcare and Government

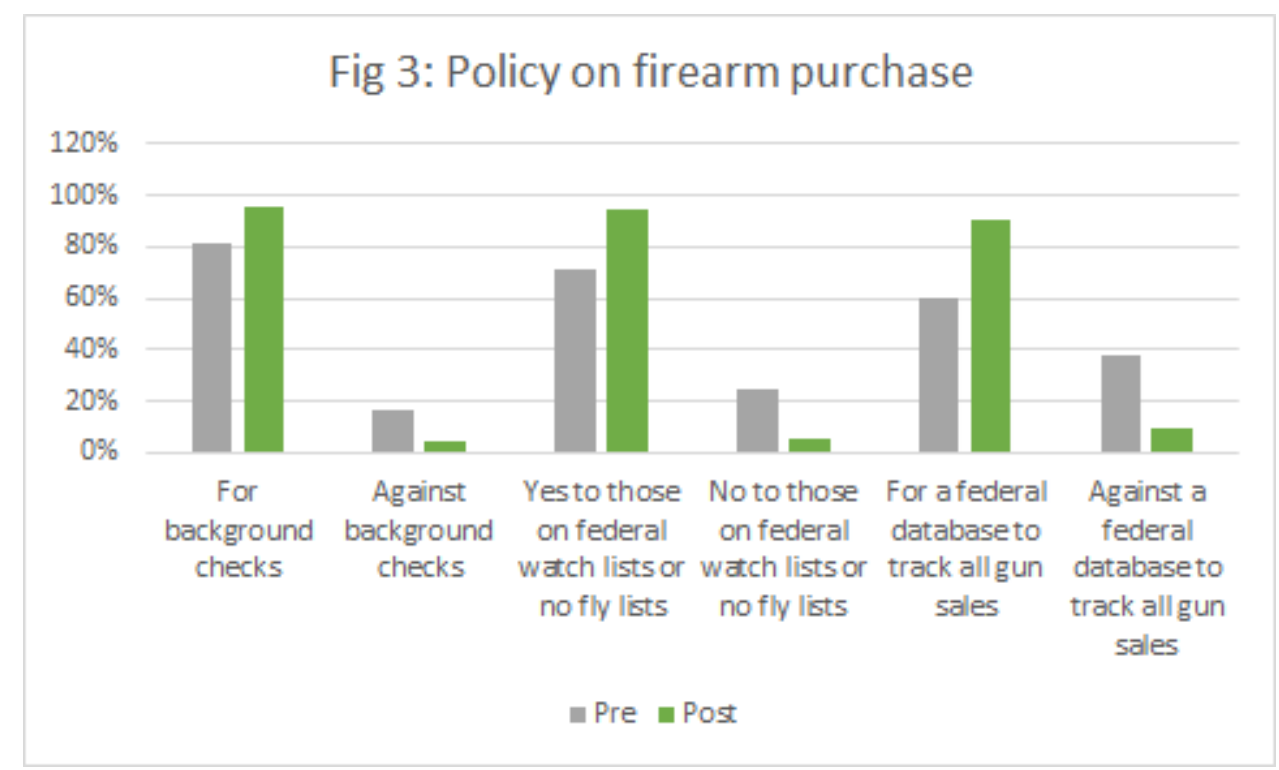

Figure 3: Policy on Firearm Purchase 


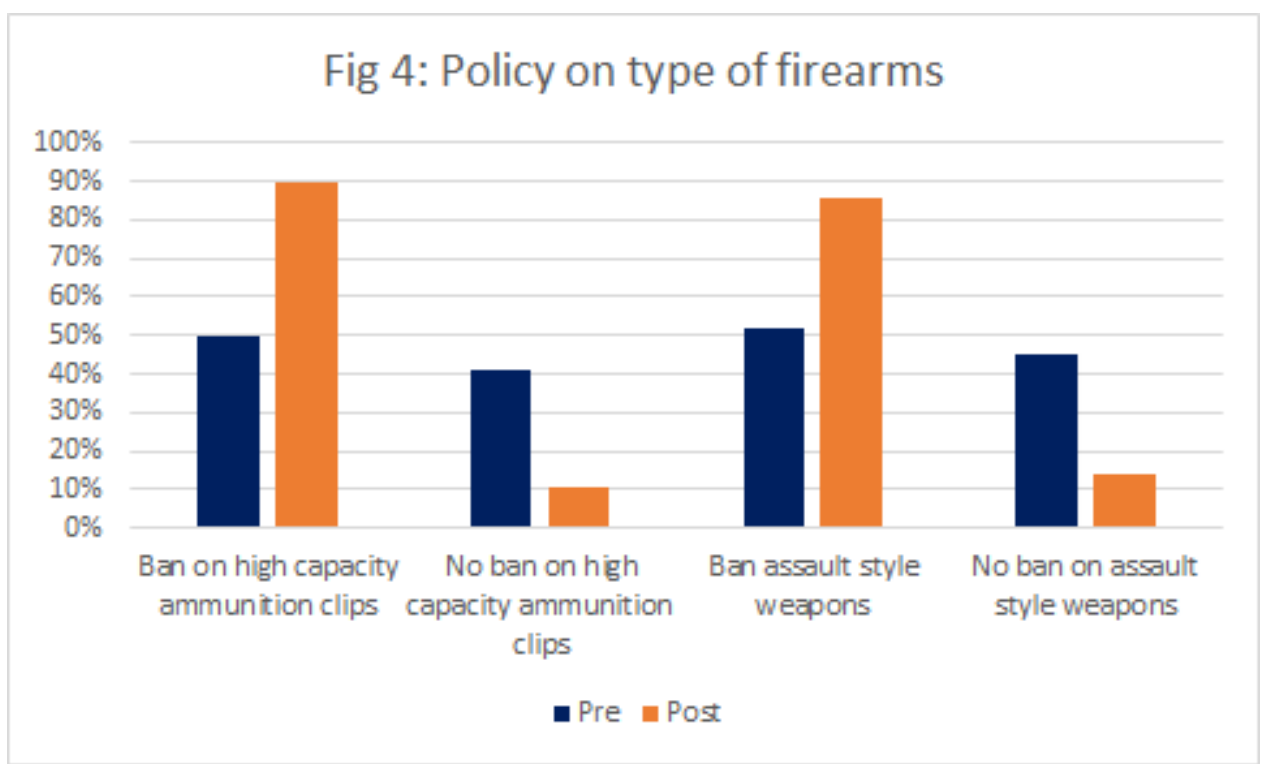

Figure 4: Policy on type of Firearms

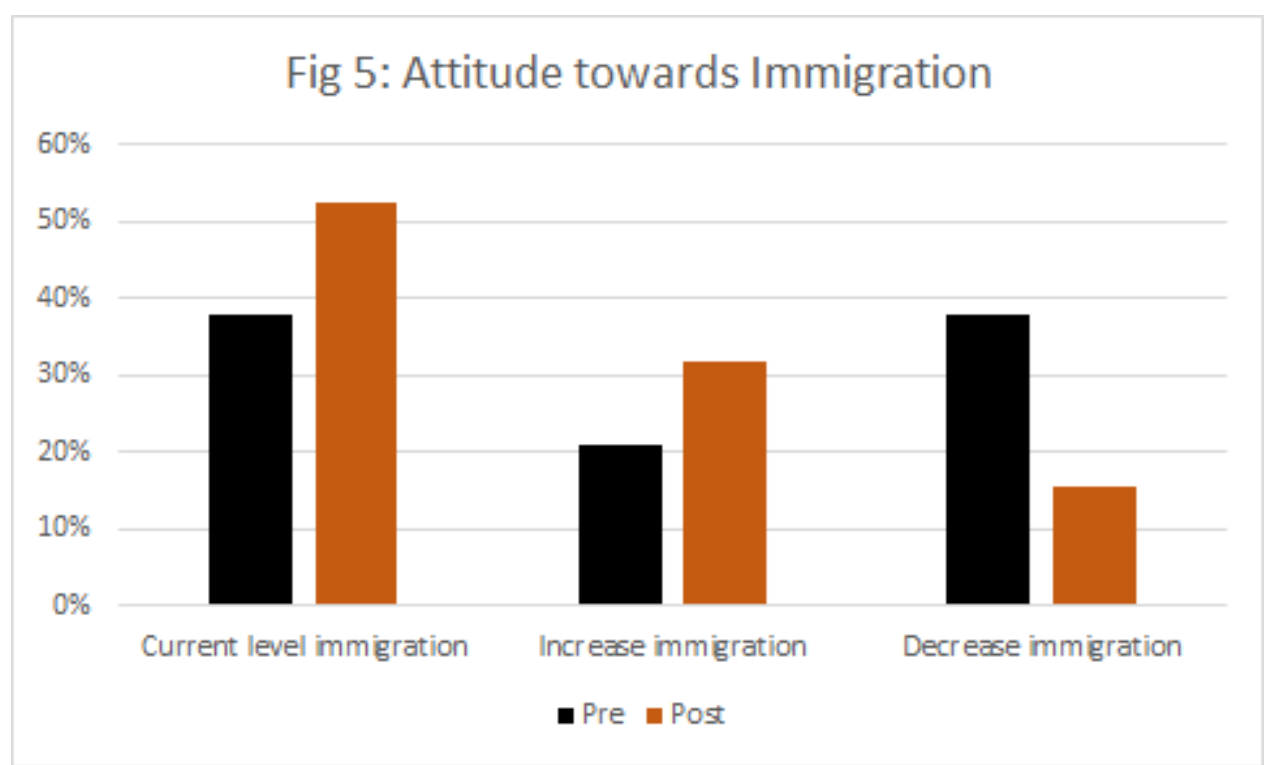

Figure 5: Attitudes towards Immigration 


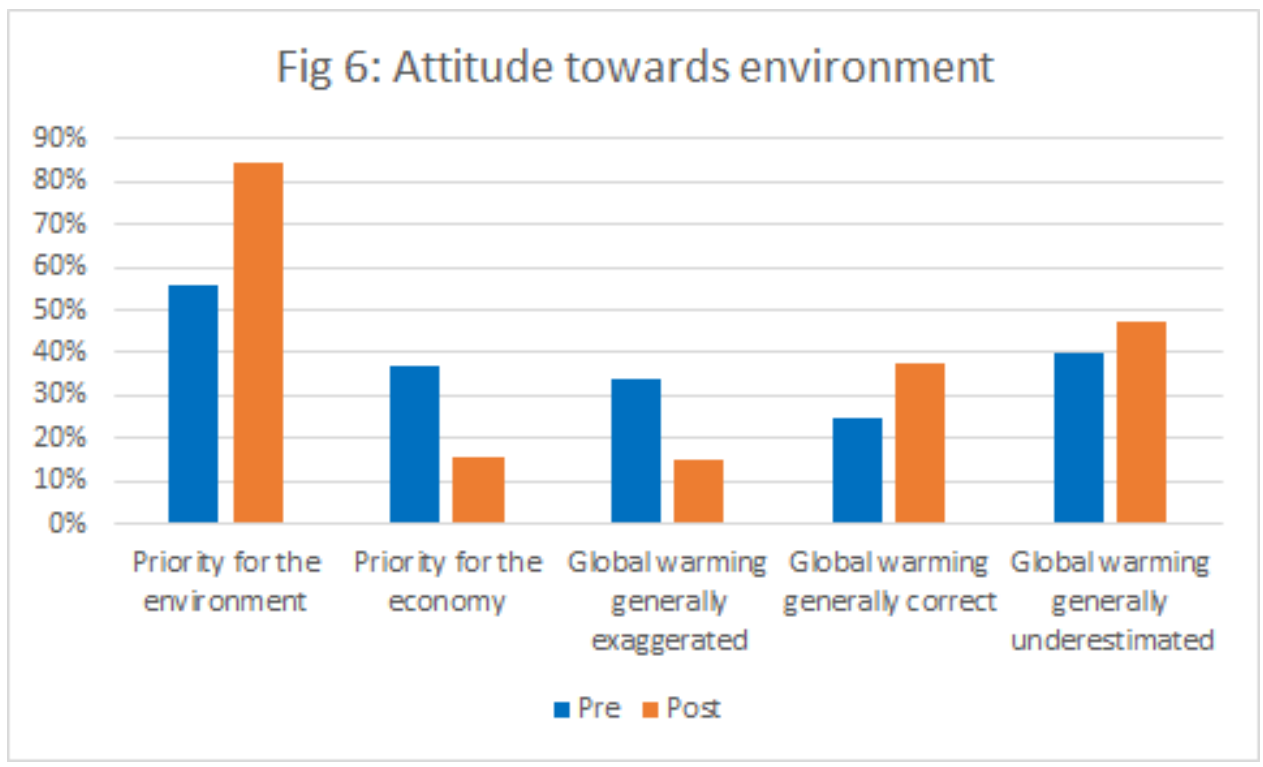

Figure 6: Attitude towards Environment

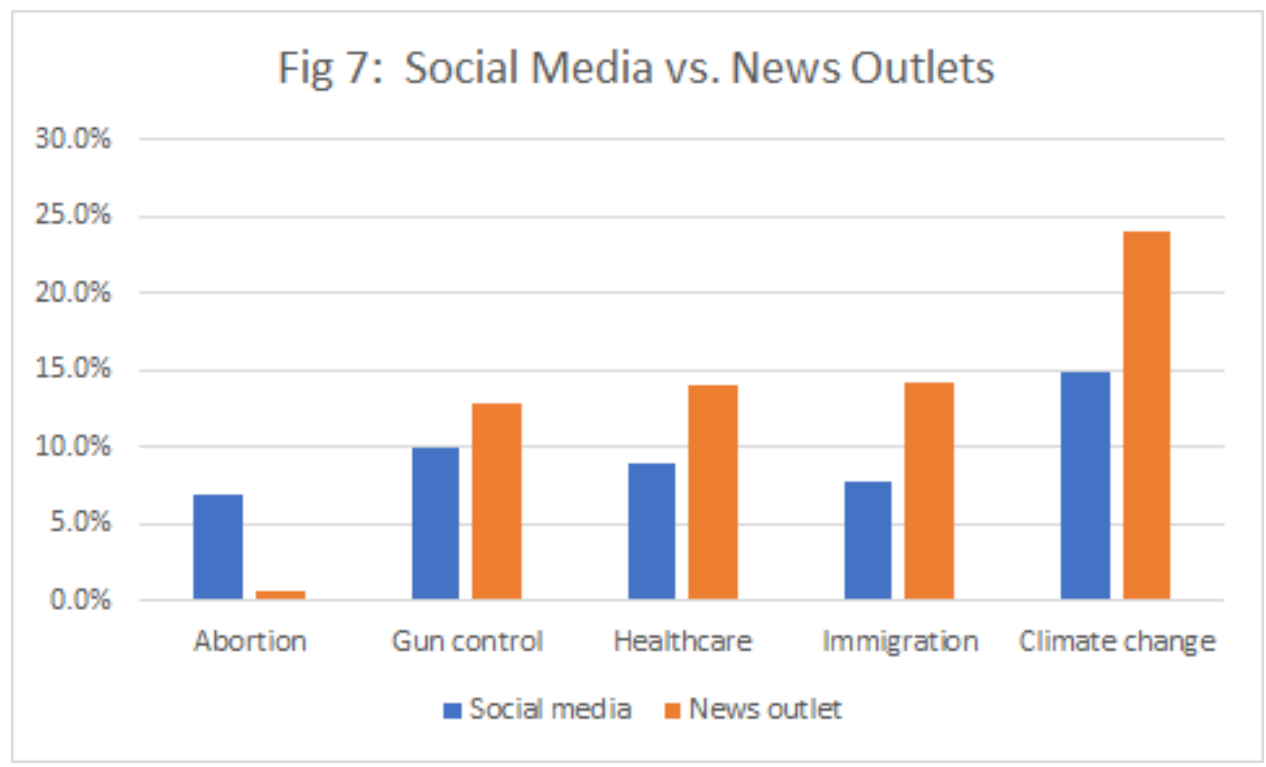

Figure 7: Social Media vs. News Outlets

\section{Discussion}

The results support the notion that the attitudes towards abortion, firearms, healthcare, immigration, and climate change have significantly changed compared to 2016 surveys. In the sample, there is a significant shift towards more liberal ideas in favor of governmental regulation, more abortion rights, more immigration, and a focus on climate change over the environment which contrasts with conservative ideas. This shift in attitudes could be multifactorial; a) a reflection of the demographic build of the sample, b) a reflection of preconceived ideas regarding Trump's political stances, and/or c) changing geopolitical scenarios. The results showed that the section with the most variance in opinion was healthcare. A significantly higher proportion of participants supported the ACA and felt that the government should play a major role in healthcare. Trump's campaign and policy promises included targeted attacks against the ACA, so it is not surprising that more people were in support of ACA in our survey as there were reports 
of millions of Americans losing insurance coverage when the law was repealed. It is also important to consider that the survey was completed in the middle of a once-in-a-lifetime pandemic which mandates major government involvement in healthcare. Due to this, the sample's higher support of the government's role could be explained to some extent with the timing of the survey. Similarly, there was a significant shift in support of abortion to be legal in some circumstances. Abortion was another key area of contention with the appointment of conservative judges, passage of multiple laws to restrict abortion and do away with exceptions for incest and medical reasons, revisiting of the Roe vs. Wade ruling, etc. A higher support towards abortion in this post Trump era survey is expected. Even some of the switches in attitudes on climate change could be a reflection of changing geopolitical realities such as the removal of US support from the Paris agreement.

In each example mentioned above, a clear trend can be identified; the Trump era made politics a personal matter. Every example includes a policy change that affected people at the individual level, whether it was access to resources, the right to control one's own body, or the attempt to create a more secure world. Because of this, it is likely that the general public is forming opinions based off of the way that they individually interact with the world, as opposed to listening to the media/politicians to form opinions. This result is reflected by the data; in all categories, the largest percentage of participants selected that their views were formed individually. It is important to note however, that the degree to which participants selected that they formed their opinions individually varied among each category. For example, abortion was the category where the most participants selected that they formed opinions on their own (89.4\%), and climate change was the category where the least did the same $(57.4 \%)$. This provides valuable insight into the way in which people form their opinions -- the debate over abortion is one that involves different subjective ideas (religion, the debate over women's rights etc.) whereas the debate over climate change is one that is determined mostly by statistics, data, and facts. The climate change debate is controlled by statistics such as the amount of time left before climate change becomes irreversible, the amount that global temperatures have increased etc.. Whether or not a person believes that climate change is a significant threat depends on whether or not they are willing to look at those scientific facts. This tells us that for more subjective political opinions, people are able to form their own opinions because, whereas for more objective political opinions, people are more likely to look to media, politicians, and other authority figures to determine their beliefs.

Aside from individually formed opinions, news outlets seemed to have played a role in the formation of attitudes at a higher level than social media for all but abortion (Fig. 7). Regarding abortion, although there was very little room for informing attitudes, social media was more influential in shaping attitudes than traditional news outlets. This finding has important policy implications. Climate change as an issue has the most room for shaping public opinions suggesting that policies to educate the public regarding this issue can be very fruitful. While one in four respondent's attitudes towards climate change were shaped by news media, one in six were shaped by social media. Hence, it is important to target both news media and social media when attempting to shift opinions regarding climate change. While there is very little room in changing public opinion regarding abortion, targeting social media might be much more fruitful in this matter, given that social media can be more effective at spreading more subjective ideas.

The aforementioned analysis provides a few new concepts from the past research. First, the influences on a person's political opinions depend on the characteristics of the political debate surrounding that idea. This contextualizes (Matsubayahi et al.,2013) findings regarding the way that politicians affect the public opinion of their constituents to the present by adding an extra layer of nuance that understands people's individual relationships to politics. It also interacts with (Montiel et al.,2016) understanding of in-group and out-group politics in two main ways. First, it disproves the idea that views are formed as a result of interactions with an in-group. Second, it confirms the idea that polarization creates echo chambers, as participants in this survey seemed less likely to look to other people's opinions and views on issues like abortion. In terms of news media, the results show that the shift towards highconflict news played a minor role in shaping opinions, given that most participants were forming their opinions on their own. The last major area to consider is the relationship between Trump era rhetoric and hatred. Surprisingly, the results indicate that individuals were less likely to be xenophobic as there was a shift towards the idea that current immigration levels should be increased, which contrasts with Perez's findings. 


\section{Conclusion}

Compared to 2016 surveys there was a significant change in public opinion about various issues of contemporary importance. While there was an overall liberal shift, the amount and direction of shift varied for different issues. Attitudes towards healthcare seem to have shifted the most with a significantly higher support for the Affordable Care Act. Most respondents had made the opinions on their own with a higher proportion for those matters that were perceived as personal such as abortion. News outlets and social media seem to have played a crucial role in switching the opinions. While news outlets had more influence than social media in healthcare, immigration, firearms and climate change, social media seems to have much higher influence on abortion.

Limitations

This research has a few limitations. The first is the small sample size compared to the pre-2016 surveys. The sample size was significantly smaller because my survey had far less reach than the previous surveys. To account for this to some degree, the two sample $\mathrm{Z}$ test controls for the varied sample sizes. The second limitation is the homogeneity of the sample. Given that I was using a snowball method to disseminate the survey, the survey was being spread within mostly homogenous groups. Another possible limitation could be that the participants' responses might be colored by social desirability because the survey snowball was being conducted by specific individuals whereas the pre-2016 surveys were taken by anonymous institutions. It is possible that some of the responses were influenced by the ongoing stress of the COVID pandemic. It is well known that the pandemic has increased levels of stress, anxiety and depression. To account for this limitation the survey could be repeated after the pandemic subsides.

\section{Future Studies}

Future studies need to disseminate the surveys within groups on social media platforms that were explicitly aligned with different ends of the political spectrum, to ensure that the sample would be as heterogeneous as possible. Future surveys need to be conducted by anonymous institutions, over a wide geographic areas and at a time free of extraneous stressors such as a pandemic.

\section{Acknowledgments}

I would like to thank my advisor Lee Conrad for helping me with this research.

\section{References}

Forgette, R., \& Morris, J. (2006). High-Conflict Television News and Public Opinion. Political Research Quarterly, 59(3), 447-456. Retrieved December 11, 2020, from http://www.jstor.org/stable/4148045

Gallup. (2021, February 11). Abortion. Retrieved February 25, 2021, from https://news.gallup.com/poll/1576/abortion.aspx

Gallup. (2021, February 11). Environment. Retrieved February 25, 2021, from https://news.gallup.com/poll/1615/Environment.aspx

Gallup. (2021, February 18). Immigration. Retrieved February 25, 2021, from

https://news.gallup.com/poll/1660/immigration.aspx

MATSUBAYASHI, T. (2013). Do Politicians Shape Public Opinion? British Journal of Political

Science, 43(2), 451-478. Retrieved November 13, 2020, from http://www.jstor.org/stable/23526236 
McDonough, J. (2016, November 07). The 2016 ELECTION reveals the differences on health care are deeper than ever: Health AFFAIRS BLOG. Retrieved February 25, 2021, from https://www.healthaffairs.org/do/10.1377/hblog20161107.057496/full/

Montiel, C., Umel, A., \& De Leon, M. (2016). Discursive Construction of Political Categories and Moral Fields: God Versus Rights and Access in a Reproductive Health Legislative Debate. Political Psychology, 37(6), 853-866. Retrieved November 12, 2020, from http://www.jstor.org/stable/44132931

Nacos, B., Shapiro, R., \& Bloch-Elkon, Y. (2020). Donald Trump: Aggressive Rhetoric and Political Violence. Perspectives on Terrorism, 14(5), 2-25. doi:10.2307/26940036

Opinions on gun policy and the 2016 campaign. (2020, May 30). Retrieved February 25, 2021, from https:/www.pewresearch.org/politics/2016/08/26/opinions-on-gun-policy-and-the-2016-campaign/

Pérez, E. (2015). Xenophobic Rhetoric and Its Political Effects on Immigrants and Their Co-Ethnics. American Journal of Political Science, 59(3), 549-564. Retrieved November 25, 2020, from http://www.jstor.org/stable/24583082

Poole, K. T., \& Rosenthal, H. (2007). On Party Polarization in Congress. Daedalus, 136(3), 104-107. http://www.jstor.org/stable/20028136

Smith, G., \& Searles, K. (2013). Fair and Balanced News or a Difference of Opinion? Why Opinion Shows Matter for Media Effects. Political Research Quarterly, 66(3), 671-684. Retrieved December 11, 2020, from ttp://www.jstor.org/stable/23563173 